\title{
La muerte en José Luis L. Aranguren ${ }^{1}$ \\ Death in José Luis L. Aranguren
}

\author{
CARLOS GÓMEZ SÁNCHEZ \\ UNED (España)
}

Recibido: 28.06.2019

Aceptado: 13.12.2019

\section{RESUMEN}

Tras delinear los intereses y líneas básicas del pensamiento de Aranguren, se consideran sus reflexiones sobre el tema de la muerte, principalmente en su Ética de 1958, pero también en artículos y obras posteriores.

PALABRAS CLAVE

ARANGUREN; ÉTICA; FILOSOFÍA DE LA RELIGIÓN; MUERTE

ABSTRACT

After delineating the interests and basic lines of Aranguren's thought, his reflections on the subject of death are considered, mainly in his 1958 Ethics, but also in later articles and works.

\section{KEYWORDS \\ ARANGUREN; ETHICS; PHILOSOPHY OF RELIGION; DEATH}

\section{LíneAs fundamentales del PENSAMiento de Aranguren}

QUiZÁ CONVINIERA, ANTES DE ENTRAR propiamente en el tema de la muerte en José Luis L. Aranguren, esbozar, aún muy sintéticamente, las líneas fundamentales de su pensamiento, en las que aquel tema ha de enmarcarse y desde las que se pueden entender mejor sus implicaciones y resonancias en los diversos ámbitos de su producción.

Desde esa perspectiva, podríamos decir que la reflexión de Aranguren giró en torno a tres ejes fundamentales: la religión, la ética y la política. El

1 Este trabajo es una revisión actualizada de otros trabajos previos que el autor ha publicado, como especialista, en otros lugares sobre Luis Aranguren. Especialmente «El plural legado filosófico de Aranguren», Endoxa 12 (2000), 341-358. El autor ha dado forma, confeccionado un trabajo original, elaborando esos materiales previos para adecuarlos al tema específico de la muerte en José Luis Aranguren.

Claridades. Revista de filosofía 12/1 (2020), pp. 369-390

ISSN: 1889-6855 ISSN-e: 1989-3787 DL.: PM 1131-2009

Asociación para la promoción de la Filosofía y la Cultura (FICUM) 
interés por el fenómeno religioso fue, en efecto, el primero, cronológicamente hablando, al que dedicó atención y que nunca abandonó del todo. El día de su fallecimiento, TVE emitió una larga entrevista que, no mucho tiempo antes, había mantenido con Fernando Delgado, sorprendido de lo que denominaba «catolicismo a machamartillo» de Aranguren, por más que su religiosidad estuviese muy alejada de la de Marcelino Menéndez Pelayo, a quien, como se sabe, se debe la expresión. Como Antonio García-Santesmases ha subrayado alguna vez ${ }^{2}$, esa actitud reflejaba la curiosidad con la que determinado pensamiento, supuestamente progresista, trataba de encajar un dato que no cuadraba en su imagen de Aranguren. Para muchos, si no para la mayoría, su imagen se vinculaba con el antifranquista valeroso, que llegó a perder su cátedra por enfrentarse a la dictadura; con el intelectual vigilante de la vida ética, social y política de su tiempo. Aranguren fue todo eso, pero sin renunciar en ningún momento a una profunda religiosidad, que le acompañó a lo largo de toda su vida. Quizá su obra más importante desde el punto de vista de la filosofía de la religión - y por la que él mismo sentía predilección, según manifestó en las Primeras Conferencias Aranguren - sea Catolicismo y protestantismo como formas de existencia (1952), en donde la apertura al protestantismo no le impedía reivindicar algunos aspectos del talante católico, en particular por lo que se refiere a no ver en la angustia y en la desesperación, por humanas que puedan ser, las únicas vías, o las vías por excelencia, de acceso a lo religioso, pues junto a ellas también cabe hablar —en medio de las zozobras que acechan toda vida humana- de diversas formas de plenitud y de paz e incluso, como luego dirá, de una «ética del contento» y del «reencantamiento», a no confundir con un fácil optimismo ciego ante el mal, sino más bien tono moral que le hace frente, procurando no embarrancar en él. $\mathrm{Y}$ asimismo es notable El protestantismo y la moral, donde rastrea las fuentes nominalistas de la teología luterana.

Pero quizá el libro que más le dio a conocer fue Catolicismo día tras día. A él se refirió el psiquiatra cordobés Carlos Castilla del Pino en el número en homenaje a Aranguren, publicado por la revista Isegoría con motivo de su fallecimiento, y en el que deja un hermoso testimonio que me parece

\footnotetext{
2 García-Santesmases, A., "José Luis Aranguren: cristiano heterodoxo», A Distancia, 1997, pp. XXIX-XXXI de los Cuadernos de Cultura (dedicados ese año a Aranguren, en ellos colaboramos también J. Muguerza y yo mismo).
} 
significativo recoger, por dar bien el tono de lo que la obra supuso:

«Dejé de ser católico — comienza diciendo Carlos Castilla del Pino- hacia los catorce o quince años, cuando el catolicismo era socialmente imprescindible. Impregnaba todo el medio social español y, sin contención alguna, se introducía impertinente, hasta en la privacidad. En España — hablo de los años cuarenta y hasta los sesentahabía que tomar posición respecto del catolicismo y el católico. El socialcatolicismo, el poder católico, era el poder. Un catolicismo ñoño, cursi, blando en apariencia, pero despiadado hasta la crueldad llegado el caso (y llegaba a las primeras de cambio) [...]. Buena parte de las energías de muchos españoles se consumían en la tarea de ser anticatólico. A diferencia del de entonces, el catolicismo de ahora no es el poder, sino un poder - y en franco declive - [...]. Aquel catolicismo al que repudiaba con todas mis fuerzas era el catolicismo español, estrictamente vaticanista. En Francia las cosas podían ser diferentes [...]. De pronto, pero aquí, apareció Catolicismo día tras día, de José Luis López Aranguren. Un libro transparente, un libro culto, moderno, inusual para ser de un católico español [...]. A aquel católico que había tras Catolicismo se le podía escuchar y se le podía leer. Se podía ir con él hasta el límite, que no teníamos derecho a sobrepasar, de su pensar y sentir lo religioso. Si su catolicismo era suyo, también reconocía el carácter de íntimo de la religiosidad (o no religiosidad) de su interlocutor, y era, por parte de él, respetado [...]. El libro suscitó una reacción tan violenta en los medios católicos más ortodoxos como para que no pudiéramos desatenderlo de ninguna manera $[\ldots]$. A medida que Aranguren era objeto de sospecha y perdía el respeto de la ortodoxia, se lo prestábamos los agnósticos y, desde luego, los heterodoxos». ${ }^{3}$

Con todo, y por importante que fuera, al propio Aranguren le pareció después tímido y lo rehizo en su Contralectura del catolicismo (1978). E incluso en su etapa americana, cuando la época del forzado exilio en la Universidad de California, seguía puntualmente los acontecimientos y las publicaciones que en ese ámbito se producían fuera y dentro de nuestras fronteras (H. Cox, H. Küng, J. Moltmann, o, entre nosotros, A. Fierro, M. R. Mate, y un largo etcétera). Y, tras el restablecimiento de la democracia, presidió, junto a José Gómez Caffarena, el Foro del Hecho Religioso, que se celebraba anualmente en Madrid, como espacio de discusión multidisciplinar entre creyentes y agnósticos de muy diversos tipos — del propio Castilla del Pino antes citado a Ignacio Sotelo, Victoria Camps, Adela Cortina, Javier Muguerza, Fernando Savater o Eugenio Trías, entre muchos otros-, unidos por el común denominador de un talante abierto y dialogal, tal como el propio Aranguren reflejaba en la crónica del mismo que cada año ofrecía en las páginas del diario El País.

3 Castilla del Pino, C., «Recuerdo de José Luis L. Aranguren», Isegoría, 15 (1997), pp. 3940. 
En uno como el nuestro, en el que la cultura religiosa —o mejor, la incultura — ha dado, y en cierta medida sigue dando, abundante pasto a todo el que ansíe un género de receta, a un variado espectro de actitudes agavilladas por su común simplicidad, Aranguren opuso a ellas su cristianismo heterodoxo, esto es, de otra opinión respecto a las instancias autoritarias de variado signo, siempre más ardientes en la búsqueda de fórmulas que encapsulen el tema que preocupadas en plantearlo. De ahí su interés por el protestantismo, por Lutero, por Kierkegaard, por ese semiprotestante que fue Pascal, por la teología de Karl Barth y sus sucesores y, entre nosotros, por Unamuno; su interés por fenómenos religiosos que ni acababan de estar dentro de las iglesias ni por eso se situaban automáticamente fuera, sino que venían a hacer resbaladizas, permeables, inestables y difusas las fronteras; su interés también por las corrientes derivadas de la Ilustración y los movimientos políticos y sociales que han canalizado, y, a la postre, su inconformismo con esas etiquetas que más que distinciones oportunas buscan, para decirlo unamunianamente, un mote - católico, protestante, agnóstico, ateo, místico, racionalista—, cuyo claro significado se desconoce, pero en el que descansa el espíritu en su pereza ${ }^{4}$. Más eclesial que eclesiástico-institucional, Aranguren, sin renunciar a sus convicciones para abandonarse a un cómodo irenismo, rechazó el tono dogmático (no sólo el de la iglesia oficial — tan torpe, además de injusta, con su figura—, sino asimismo el de otros sectores, aunque fueran de signo inverso), tono dogmático que, como ya advirtiera Rousseau en una de sus ensoñaciones, «no conviene sino a los charlatanes» ${ }^{5} \mathrm{y}$, frente al cual, parece haber hecho suyo el hermoso consejo que se puede leer en el Fedón, según el cual acerca de estos temas hay que lograr una de estas cosas: o aprender de otro cómo son, o descubrirlos por nosotros mismos, y, si nada de ello resulta posible, tomar la explicación mejor y más difícil de refutar de entre las humanas y embarcarse en ella como sobre una balsa para surcar navegando la existencia. Una navegación en la que José Luis Aranguren supo conjugar la cautela intelectual y la conciencia de los aspectos sombríos y sin sentido de la existencia con una disposición de confianza y ánimo, por la que, sin

4 Unamuno, M. de, «Mi religión» (1907), en Mi religión y otros ensayos, Madrid: Espasa-Cal-

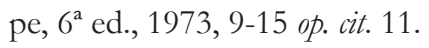

5 Rousseau, J.-J., Las ensoñaciones del paseante solitario, ed. de F. J. Hernández, trad. de C. Ortega Bayón, Madrid: Cátedra, 1986, 68. 
volver la vista ante el absurdo y el mal, evitaba quedar varado en ellos.

$\mathrm{Y}$ a la religión se refería aún en uno de sus últimos artículos publicados, «La religión, hoy», no recogido en sus Obras Completas, pero que se puede encontrar, además de en su edición original, en la antología de textos que sobre la obra de Aranguren preparé con motivo del primer centenario de su nacimiento ${ }^{6}$.

Mas, por constante que fuera su atención a los temas de filosofía de la religión, su labor no se redujo a ese campo, sino que se amplió a muchos otros y, por lo pronto y muy principalmente, a la ética. En el ámbito de la filosofía moral, Aranguren supo enraizarse en las sugerencias y elaboraciones que autores como Ortega o Zubiri habían hecho al respecto. Por lo que a Ortega se refiere, escribió, en un momento en que se pretendía condenar sus escritos, un valiente y valioso estudio sobre la ética implícita en ellos, La ética de Ortega (1958), que se sumaba a la reivindicación hecha por Julián Marías y Pedro Laín Entralgo. Aranguren también ha reconocido lo que debe al magisterio de Zubiri, cuyos cursos privados —algunos de los cuales han sido mucho más tarde publicados — pudo seguir. Pero fue Aranguren quien tematizó expresamente ese dominio en el pensamiento español. Su Ética apareció en 1958, tres años después de haber obtenido una cátedra de Ética y Sociología en la Universidad de Madrid. Es una ética del bien y de la felicidad, de inspiración reconocidamente aristotélica, pero con un Aristóteles y un santo Tomás leídos a la altura de nuestro presente y no simplemente esclerotizados en fórmulas rutinarias. Y junto a ellos se hacía presente la filosofía moderna, bien a través del diálogo crítico con Kant, bien a través del pensamiento existencial de Kierkegaard, Heidegger o Sartre, además de las frecuentes referencias a la ética de los valores de Scheler, a la filosofía analítica (Moore, Wittgenstein, Ayer, Stevenson, Toulmin...) y a la literatura, que tendía un puente entre la ethica docens, la ética en cuanto disciplina académica, y la ethica utens o moral vivida.

En un principio, y quizá por influencia de Zubiri, Aranguren subordinó la ética a la metafísica. Pero será cada vez más en la antropología, en vez de en la metafísica, donde se busque el surgimiento de la moral, con lo que, kantianamente en este caso, sería la ética la que podría dar paso a una problemática metafísica y a una apertura a la religión, al menos en forma

6 Gómez, C., José Luis L. Aranguren. Filosofía y vida intelectual. Textos fundamentales, Madrid: Trotta-UNED, 2010. 
de pregunta y como horizonte de problemas de los que la ética misma no se podía desentender, por más que para Aranguren el vector religioso desbordara los límites de cualquier eticismo.

Mas dejando ese nudo de problemas y volviendo a la base antropológica de la moral, Aranguren siguió las sugerencias de Ortega, al entender la vida humana como quehacer, y de Zubiri, cuando hablaba de la moral como estructura, al insistir en que la vida humana es susceptible de multitud de recreaciones culturales, sin que las disposiciones biológicas nos fuercen a ninguna de ellas, excepto la de forzarnos a elegir, que es a lo que Sartre se refirió con su conocida expresión de estar «condenados a la libertad». La vida humana es forzosa, constitutiva, estructuralmente moral, en el sentido al menos de que, aunque nos ha sido dada, no nos ha sido dada hecha y cada cual ha de elegir, ser el novelista —más o menos original o plagiario— de su propia vida, para lo cual es preciso no estar desmoralizado, sino con el suficiente ánimo como para acoger y afrontar las posibilidades y resistencias que la realidad nos presenta. Aun cuando tal quehacer, estructuralmente moral, puede luego desarrollarse moral o inmoralmente, debida o indebidamente, en el plano de la moral como contenido. Contenidos de la moral que suelen venir ofrecidos sociohistóricamente por las diversas culturas, religiones o visiones de sentido, pero que, so pena de permanecer en lo que Bergson denominó la «moral cerrada», pasivamente recibida del grupo dominante al que se pertenezca, cada cual habrá de apropiarse o rechazar y en todo caso reelaborar desde su propia perspectiva. Y por más que raramente se alcance la dimensión de reformador moral, todos y cada uno de nosotros hemos de recrear, en la medida de nuestras posibilidades, la vida moral. Dimensión insoslayablemente individual de la tarea ética progresivamente acentuada por Aranguren, al subrayar (así en su obra Lo que sabemos de moral, 1967, reeditada más tarde bajo el título de Propuestas morales, 1983) la importancia de la moral como actitud, pivotando sobre la autonomía de la conciencia, todo lo condicionada que se quiera (por condicionamientos biológicos, biográficos, sociales, económicos, inconscientes...), pero instancia última e irrebasable de la moralidad, que se asemeja así a la buena voluntad kantiana. Una buena voluntad que, sin desentenderse de las consecuencias, no se deja medir por ellas, y que depende de la actitud de cada individuo, aunque tal dimensión individual de la moral no equivale para Aranguren al individualismo rapaz y posesivo tantas veces 
pregonado, pues, parafraseando a Camus, ya advirtió que, aunque nuestras decisiones morales son en última instancia solitarias, ello no quiere decir que hayan de ser insolidarias.

Precisamente de la dimensión social de la moral se ocuparía Aranguren en una de sus obras más notables, Ética y Política, abriéndose a otra de las vertientes cardinales de su pensamiento ${ }^{7}$. La ética es siempre individual en el sentido de que el individuo es su agente insustituible, pero ese individualismo ético sólo puede realizarse en la apertura a los otros, bien sea que se relacione con ellos como otros concretos y personalizados — dando lugar a lo que podría denominarse ética de la alteridad—, bien aparezcan en su horizonte como esos otros innominados, desconocidos personalmente, pero respecto a los que está obligado en las tareas sociales de las que habría de ocuparse la ética de la aliedad (del otro, no como alter sino como alius) o ética propiamente social. El temple de Aranguren era más ético y religioso que político ${ }^{8}$, pero, cada vez más, ese mismo temple le condujo a interesarse por las realidades político-sociales de su tiempo, sin llevar a cabo nunca una actividad propiamente política, mas sin desdeñarla. Aunque las relaciones entre ambas esferas, la ética y la política, no le parecían de fácil armonización, se resistía a escindirlas o a ver necesariamente en ellas una relación trágica, frente a la que mantuvo la posibilidad de una tensión dramática, rechazando tanto la política carente de principios como la ética del «alma bella», que preserva su pureza a costa de la inoperancia o la evasión. Sin entrar en todos los desarrollos y propuestas que Aranguren lleva a cabo en esa obra, es preciso poner de relieve que al tema político le dedicó una atención cada vez mayor - de esa época es también su libro El marxismo como moral, 1968-, unida al interés por la sociología y las ciencias humanas, los movimientos sociales o la reflexión al hilo de las cambiantes circunstancias de la vida española. Bástenos señalar ahora que Aranguren no escatimó sus críticas a lo que consideraba injusto del sistema social y

\footnotetext{
7 Bonete, E., Aranguren: la ética entre la religión y la política, Madrid: Tecnos, 1989.

8 Así, por ejemplo, en el Prólogo de 1980 a Catolicismo y protestantismo como formas de existencia declara: «Me ocupé de religión, no porque no se permitía hablar con la más mínima libertad de política, sino porque, al revés, la política nunca me ha importado de verdad, sino desde el punto de vista ético, y que los temas últimamente capitales para mí son los sociales y morales, los culturales en general, los religiosos en particular, y muy poco los estrictamente —estrechamente- políticos. A cada uno lo suyo, y lo mío, ciertamente, felizmente también, no es la política» (en OC, I, pp. 213-214).
} 
político que le tocó vivir, no ya cuando carecía de reconocimiento público, sino precisamente cuando lo adquirió. Su radicalización creció con los años en vez de acomodarse al peso al que el paso de los mismos tantas veces incita. Una radicalización que, por lo demás, supo no jactarse de sí, sino que acertó a acompañar la seriedad de sus posiciones con la ironía y el humor que impiden el envaramiento.

En todo caso, esa actitud vigilante y crítica no sólo le había llevado en 1965 a ser expulsado de su cátedra por la dictadura franquista, sino que también le condujo — tras su exilio americano en la Universidad de California y el posterior retorno a su cátedra española, en los comienzos de la transición democrática- a no darse por contento con la democracia recién inaugurada en nuestro país, sino, aun celebrándola, insistir, así en su libro La democracia establecida: una crítica intelectual, de 1979, en la diferencia entre la democracia establecida y la democracia como moral, que es algo a conseguir cada día en muy diversos ámbitos, y no sólo en el más cerradamente político, hasta apuntar a una auténtica revolución cultural (en el sentido, no culturalista, sino antropológico del término), sin que sea concebible un estado o situación en el que pudiéramos definitivamente descansar, como sobre algo poseído de una vez por todas. De ahí que, junto a la actitud crítica, Aranguren defendiera un impulso utópico al que, en ningún caso, podríamos renunciar sin abdicar a un tiempo de nosotros mismos.

De este modo, más allá del ámbito estrictamente académico, Aranguren ejerció un notable influjo sobre extensos sectores de la sociedad española, a través de sus escritos de intervención y su actividad pública. Siempre dispuesto a participar en un debate, en una mesa redonda, en conferencias de temas muy diversos; escribiendo comentarios de libros y prologándolos; participando en diarios y revistas de amplia resonancia, pero también en otros menos notorios; dejándose entrevistar, sabiendo escuchar y tener una palabra oportuna encarnó ejemplarmente, en lo que llamó su «cátedra ambulante», el papel del intelectual, al que él mismo, sin embargo, veía declinar, para dejar paso a lo que denominaba «intelectual colectivo» ${ }^{9}$. Aranguren nunca se colocó au dessus de la mêlée, sino que supo realizar la tarea - bastante más ardua, como advertía Mairena- de estar a la altura de las circunstancias. Por no andar de vuelta, se permitió el lujo de desbrozar y re-

9 Cfr., Gómez, C., «El oficio del intelectual en J. L. L. Aranguren», Cuadernos hispanoamericanos, 786 (2015), 34-51. 
correr un amplio trecho de muchos caminos. En sus últimos años repitió, en diversas ocasiones, que aunque se sabía viejo no se sentía tal. Quizá su inusual juventud, intelectual y vital, se debiera en parte a saber conservar algo del infantil espíritu de asombro, que le curó del infantilismo de jugar a ser persona. Lo que, dicho sea de paso, le facilitó realmente serlo.

\section{LA MUERTE EN ARANGUREN}

\section{II.1. EN ÉTICA (1958)}

A pesar de, como hemos visto, sus persistentes intereses éticos y religiosos, la cuestión de la muerte no fue especialmente tematizada por Aranguren, aunque, de forma más o menos indirecta, siempre estuvo presente en su reflexión. Quizá el texto más amplio al respecto sea el último capítulo de su Ética, de $1958^{10}$, en el que se enfrenta con diversas posiciones sobre la muerte de diferentes pensadores contemporáneos y, a través de ellos, decanta la suya propia, siendo Sartre, Rilke y Heidegger los principales autores a los que tiene en cuenta, además de la influencia en su pensamiento de Zubiri. Y en ese debate, elabora Aranguren una tipología de actitudes ante la muerte (la muerte eludida, la negada, la apropiada, la buscada, la muerte absurda) para concluir con un sentido ético de la muerte.

Comenzando por la muerte eludida, Aranguren no tiene en cuenta, pues aún no se había publicado, el excelente estudio de Ph. Ariês, El hombre ante la muerte ni la versión reducida que el propio Ariês había hecho del mismo en Historia de la muerte en Occidente, los cuales le habrían servido en buena medida para apuntalar su tesis respecto a la muerte eludida ${ }^{11}$. En ellos, Ariès señala cómo en la sociedad actual se trata de escamotear la muerte, atribuyéndola a la casualidad («si no hubiera tomado ese avión, si la ambulancia hubiese llegado a tiempo...»), cómo se preserva de ella a los niños - pese a que, en los cuadros clásicos de moribundos, es difícil que se les haya sacado de la escena- y cómo, en definitiva, se la niega, cuando no se la tapona entre una red de tubos, aparatos y salas de hospital, de manera

10 Aranguren, J. L. L., Ética, en Obras Completas, ed. de F. Blázquez, 6 vols., 1994-1996, II, pp. 486ss.

11 Ariès, Ph., El hombre ante la muerte, trad. de M. Armiño, Madrid: Taurus, $4^{a}$ ed., 1992 (ed. original en francés, París: Seuil, 1977); Historia de la muerte en Occidente, de la Edad Media hasta nuestros días, trad. de E. Carbajo y R. Perrin, Barcelona: Acantilado, 2000 (ed. original en París: Seuil, 1975) 
que lo que nos llega de la muerte es ante todo la muerte-espectáculo de las noticias o de la televisión.

Tampoco tiene en cuenta Aranguren los diversos estudios de Freud al respecto, al que solo cita de pasada, en el apartado de la muerte buscada, al hablar del impulso tanático. Pero le hubiera sido muy valioso, pues va en una dirección similar a sus propias reflexiones, el hermoso, aunque sombrío, estudio de Freud Consideraciones de actualidad sobre la guerra y la muerte ${ }^{12}$. Freud quiso hacer notar que el considerar la muerte como una casualidad no estaba sino al servicio de una ilusión (de una ilusión ilusoria, quería decir; no todas lo son) y lo malo de esas ilusiones es que a veces chocan con un trozo de realidad y saltan hechas pedazos. Si alguna ventaja aportó la Gran Guerra de 1914-1918 es ponernos cara a cara frente a la muerte y obligarnos a aceptar que todos, en efecto, hemos de morir: son tantas balas, tantos cadáveres que ya no vale escudarse en la casualidad. Es cierto que en lo inconsciente, que no conoce la negación, todos nos consideramos inmortales. Pues aunque desde pequeños sepamos que vamos a morir, revestidos de narcisismo y omnipotencia, sobre todo en la juventud, no nos lo creemos y eso es lo que presta a veces una simulada heroicidad. La creencia en la muerte sólo empieza a asentarse en nosotros a través de la de personas queridas, con las que se nos van objetos de amor muy preciados y con cuya desaparición, a través de la identificación con ellas, la realidad nos arranca a nosotros mismos también un buen pedazo y nos va haciendo aceptar que todo, también nuestro amado yo, ha de morir. Frente al intento de escamotear el carácter ineluctable de la muerte, que nos tratamos de ocultar, Freud anima a hacerse cargo de ella, no para exaltarla, sino, antes al contrario, para que cuidemos mejor, mientras podamos, de la vida misma. Por eso propone cambiar el viejo adagio latino Si vis pacem, para bellum, «si quieres la paz, prepárate para la guerra», por otro que dijese: Si vis vitam, para mortem, «si quieres vivir, prepárate para morir».

Pues bien, aunque Aranguren se mueve en un plano ético, diferente al de los historiadores o los psicoanalistas, sus consideraciones se encuentran aquí muy cercanas y expresan bien, a mi entender, un rasgo característico

12 Freud, S., en Obras Completas, trad. de L. López-Ballesteros y de Torres, Madrid: Biblioteca Nueva, $3^{a}$ ed., 1973, T.II. Un análisis del conjunto de su producción lo llevé a cabo en Freud y su obra. Génesis y constitución de la Teoría psicoanalitica, Madrid: Biblioteca Nueva - Asociación Psicoanalítica de Madrid, 2002 (3ª ed., 2014). 
de nuestra época, que, en sus líneas esenciales, aún perdura. La muerte permanece en nuestras sociedades como algo inexpresado, en todo caso aludido, pero siempre eludido, como si ser conscientes y hacernos cargo de que vamos a morir fuese un pensamiento perturbador y paralizador de la vida. Y ya que el hombre no puede eliminarla, trata al menos de eliminar la preocupación por ella. A ello ayuda la imposibilidad de tener una imagen de nuestra propia muerte, que podemos pensar, pero no imaginar, pues incluso el hombre que lo intenta permanece contemplando su entierro, sin que su yo sea nunca imaginativamente eliminado. Y a esa imposibilidad de representación se agrega la represión del pensamiento de la muerte, particularmente durante la juventud, que suele considerar que el plazo es muy largo y tiene mucho tiempo por delante. Quizá esta sea, observa, una de las fuentes de la enorme valoración e idealización que se hace de la juventud, cuyos hábitos, modales y atuendo se tratan de imitar, en la ilusión de permanecer siempre jóvenes y así mantener a raya el pensamiento de la muerte. $\mathrm{Y}$ a ese afán colaboran tanto la esperanza pseudocientífica de poder llegar algún día a postergarla indefinidamente, deslizándose así de la negación del pensamiento de la muerte a la negación de su misma realidad, como el alejamiento cada vez mayor de la naturaleza, que llega a caracterizar la muerte como algo accidental, por simple azar o porque aún no se ha descubierto el remedio para ella, las medicinas que podrían curarnos de su afección.

La muerte que vivimos es entonces siempre la muerte del otro, la muerte como espectáculo, al que otorgamos en todo caso un carácter fortuito o que pretendemos maquillar, como se maquilla a los muertos para hacerlos presentables y tratarlos, no como «hombre muerto», como «otro yo» que acaba de morir, sino como cosa, como algo asumible, que nos permite de nuevo eludir la muerte, la cual, en definitiva, no nos debe preocupar. Y aquí Aranguren recuerda la célebre sentencia de Epicuro: no habríamos en efecto de preocuparnos por la muerte, porque mientras vivimos no ha llegado y cuando llegue ya no estaremos y serán los otros quienes hayan de ocuparse de mi muerte. En cualquier caso, concluye,aunque mi muerte nunca llegará a hacérseme presente, sí puedo sentirla acercándose, verla venir. $\mathrm{Y}$ por eso se hablaba tradicionalmente de prepararse para bien morir (como los psicoanalistas hablan de tratar de elaborar anticipadamente, de alguna forma, el duelo por la propia existencia, lo que permitirá, quizá, 
una vejez menos irritada al ver cercenarse las posibilidades y una muerte mejor), preparación para la muerte que hoy más bien se vuelve en su contrario, en la insensibilización hacia la muerte, de forma que la muerte propia se sustrae lo más posible de la conciencia de los vivos

Los intentos, si no de eludirla, sí de extraterritorializar la muerte, a la manera de Epicuro, intercalo ahora yo, se han repetido en más de una ocasión. Y por poner un caso eminente, ahí está el de ese marxista peculiar que fue Ernst Bloch ${ }^{13}$. Sin embargo, aunque podamos conceder que mientras vivo no ha llegado, ese tipo de argumentación no deja de ser una forma espuria de consuelo: aun no habiendo definitivamente llegado, siempre se proyecta sobre nuestras vidas, pues, como desde antiguo (Séneca) se observó, «apenas hemos nacido, ya somos suficientemente viejos para morin». Y es que, aunque pretendamos distraernos de ello, que la muerte es ineluctable es de las cosas más ciertas que tenemos y ha sido en ocasiones bellamente puesto de manifiesto. Piénsese en El séptimo sello de I. Bergman, por aludir a una obra cinematográfica, que sigue conservando su enorme fuerza expresiva. También ahí, la primera vez que el caballero se encuentra con la muerte, parece que, distraído en un quehacer, no puede atenderla y le dice: «Espera un momento», pero la muerte, inflexible, le responde: «Eso me piden todos». El caballero trata de ganarle la partida de ajedrez que entablan y, contento de encontrar una buena jugada que cree le pone a salvo, se lo comenta al confesor. Pero quien sale del confesionario es la muerte misma que se había colado en él y se aleja diciéndole: «Gracias». Así también en el cuento oriental, en el que un criado sale a pasear por el jardín del visir de Bagdad, se tropieza con la muerte y regresa aterrorizado pidiéndole a su señor que le deje ir a Samarra, para protegerse junto a su familia. El visir le deja marchar y sale él mismo a pasear por el jardín donde todavía se encuentra la muerte a la que le increpa: «No me gusta que mires amenazadoramente a mis criados». Pero la muerte le replica: «No le he mirado amenazándole. Le he mirado con sorpresa. Me ha sorprendido verle esta mañana en Bagdad, cuando tengo una cita con él esta noche en Samarra».

Pero, volvamos con Aranguren. Junto a la muerte eludida, el segundo

13 De Ernst Bloch me he ocupado en diversas ocasiones. Cfr., entre otros lugares, el capítulo «Ética y utopía» en C. Gómez y J. Muguerza, La aventura de la moralidad. Paradigmas, frontera y problemas de la ética, Madrid: Alianza, 2007 (6 ed. 2016). 
tipo de actitud respecto a la muerte que considera es la muerte negada, que no consiste sino en querer quitarle su gravedad y considerarla como un simple pasaje. Actitud a la que puede ser propenso, entre otras corrientes, cierto cristianismo exultante. Mas pensar la muerte como un rápido y más o menos cómodo paso a la inmortalidad, puede ser otra manera de eludir su gravedad existencial. Y aunque quizá quepa una actitud «natural» hacia la muerte, según la cual se muere casi como se nace, con conformidad y sosiego, Aranguren piensa que para el hombre de nuestro tiempo, tan lejos de la naturaleza, tal actitud suele ser inadoptable y se reduce más bien a una forma de fingimiento. Pues incluso los místicos, que deseaban llegar cuanto antes al «encuentro» (no puedo dejar de recordar a este respecto una hermosa cuarteta, en la que enlazando goce y muerte -como de algún modo, aunque en diferente sentido, harán en nuestros días los lacanianosse decía: «Ven muerte tan escondida,/ que no te sienta venir,/ porque el goce de morir/ no me vuelva a dar la vida»), hablaban, así Juan de la Cruz, de «los aprietos de la muerte» y del morir como «subir por el desierto de la muerte».

Pero, ¿no hay veces que se quiere, en efecto, morir y la muerte, más que eludida o negada, es buscada? El presupuesto de tal actitud, estima Aranguren, es la creencia en la nada tras la muerte, bien creyendo que tras la muerte no hay nada, bien creyendo que lo que hay tras la muerte es la nada. Y mientras el primer caso implicaría la pretensión de apropiación total de la muerte, que dependería absolutamente de nuestra voluntad, con lo que el morir sería una más de las cosas que se pueden hacer (lo que enseguida vamos a considerar), el segundo, al contemplarla como descanso y algo positivo, vendría a reducirse a otra de las formas de la muerte negada.

Vayamos, pues, con la muerte apropiada, de la que acabamos de hablar. Si en la muerte eludida o negada, se tiende a considerar la muerte como algo contrario y extrínseco a la vida, también ha habido quien, por el contrario, la consideraba coextensiva con la vida misma, como en la cita de Séneca que más arriba consignamos, pues, dado que no solo morimos, sino que también sabemos anticipadamente que vamos a morir, la muerte proyecta su sombra sobre la totalidad de la existencia y no solo es algo que ocurrirá «luego» o en un futuro remoto e indefinido. Ahí es donde Aranguren pretende considerar los que a su juicio son los dos grandes intentos de apropiación de la muerte en nuestro tiempo: el de Rilke y el de 
Heidegger. Si la muerte es el término de la vida, estima Rilke, pertenece a ella y, como acto final, debo incorporarla, de forma que sea preparada y conformada por mí, y sea mi muerte propia. Pero, para Aranguren, esa concepción, además del riesgo esteticista — aunque sea de un esteticismo trágico- que comporta, incurre en la desmesura de pensar que la muerte es solo un acto del muriente, olvidando que, lo quiera o no, es también un destino suyo, algo que se hace con él y no solo que él hace.

En cuanto a la distinción heideggeriana entre la muerte como hecho, la terminación física de la vida, y la muerte como cuidado o pre-ocupación, la primera, estima, resulta completamente inapropiable, pues es en todo caso, como quería Epicuro, externa a la vida o, a lo sumo, tangencial a ella: no me afecta a mí, sino a los otros, familiares o amigos. La segunda, en cambio, nos permite anticiparla, sobre todo en la angustia; no realmente, pero sí existencialmente, de forma que el puro hecho se convierta en suprema posibilidad y el destino en acto libre. Pero esto solo es posible, estima Aranguren, desdeñando precisamente el acontecimiento real, para no retener más que el cuidado. Tamaña pretensión olvida, sin embargo, que hay algo que no puede llegar a humanizarse ni a anticiparse por el pensamiento, sino que sigue ahí frente a nosotros, resistente y opaco, y que es precisamente la hora de la muerte, el acontecimiento real de la muerte, del que Heidegger se desentiende.

Con esto llegamos a la quinta actitud, la muerte absurda, a propósito de la cual su principal interlocutor es Sartre. Frente a Heidegger, Sartre piensa que la muerte no es una posibilidad mía y mucho menos mi posibilidad suprema, sino, al contrario, la negación de todas mis posibilidades. Y en cuanto al hecho de la muerte, desdeñado por Heidegger, para Sartre es puro azar y contingencia, exterioridad que priva a la vida de toda significación; no es una estructura ontológica de mi ser, sino que solo el otro puede dar sentido a nuestra muerte. Para mí, mi muerte es simplemente absurda.

Al final, Aranguren propone su propia visión de la muerte y su posible sentido ético desde una concepción de fondo cristiana. Ineludible e inapropiable, la muerte no puede ser humanamente comprendida, pero esto no tiene por qué querer decir, frente a Sartre, que sea simplemente absur$\mathrm{da}$, sino que puede concebirse como formando parte del misterio que nos ciñe. Si muriésemos solo ante los hombres, la muerte sería absurda, porque pueden disponer abusivamente de algo que no conocieron más que 
en su exterioridad, pero si morimos ante Dios, se engloba en el misterio mismo de la vida que nos comprende y abarca a nosotros mismo. Con lo cual nos vemos abocados a elegir entre el absurdo o el misterio.

¿Y qué sentido ético podemos dar a la muerte? Apoyándose en Zubiri ${ }^{14}$, Aranguren piensa que el tiempo no es solo duración o, como quería Heidegger, futurición, sino asimismo emplazamiento. Tenemos los días contados y eso implica que la vida en un «mientras», en el que, negativamente, caminamos, sí, hacia la muerte, pero, positivamente, permite la autodefinición y la apropiación de posibilidades, que van configurando y determinando nuestro modo de ser, hasta que llega la hora de la muerte, en la que nuestro êthos queda definitivamente fijado.

Ya antes. Aranguren había abordado con algún mayor detalle su concepción de la muerte, cuando trató, al comienzo de la segunda parte de su Ética, la estructura circular de la misma entre actos, hábitos y carácter, para señalar que, sin restar importancia a los mismos, quizá lo que ante todo importe es el sentido que hemos dado al conjunto de la vida, de la que aquellos forman parte. Y se pregunta si es posible tener ante sí, junta y apretada, la vida en su unidad, pese a ser pura distensión temporal ${ }^{15}$. Y responde que ello es posible en determinados actos privilegiados, que serían el «instante», la «repetición»y el «siempre».

«Los actos privilegiados en cuanto a la profundidad y reasunción que en ellos se alcanza son el "instante", la "repetición" y el "siempre". El concepto de los dos primeros fue forjado por Kierkegaard y desarrollado luego por Jaspers y por Heidegger. El "siempre" se debe a Xavier Zubiri. El acto privilegiado desde el punto de vista del kairós es la "hora de la muerte"».16

El «instante» es, por decirlo así, la eternidad en el tiempo, tangencia de lo eterno y lo histórico, un acto momentáneo (aunque haya venido preparado desde tiempo atrás, como sucede en el fenómeno de la conversión, sea esta ética, religiosa o ético-religiosa) en el que el hombre elige su existencia en un «golpe de vista» decisivo, echado desde la profundidad de un «presente auténtico».

La «repetición» consistiría en la asunción, también en un instante, de la totalidad de la vida, como dicen que sucede a veces en quien va a morir,

14 La influencia de Zubiri en estos pasajes de Aranguren está subrayada en Bonete, E., «Aranguren: sentido ético de la muerte», Revista de Hispanismo filosófico, 13 (2008), 75-89. 15 Aranguren, J. L. L., Ética op.cit., pp. 308ss.

16 Inidem, pp. 311-312. 
que recorre en un momento, concentradamente, su decurso temporal y lo repite reasuntivamente, esto es, no como mero espectador, sino como su autor responsable.

Para Zubiri, el «siempre», el «de una vez por todas», es el fundamento de la mutación temporal y la intensión en él otorga la posesión de sí mismo.

Mas, sin poder entrar ahora en el desarrollo de estos temas, a los que Aranguren ha dedicado pasajes muy hermosos, lo que nos importa destacar es que esos actos —o actualizaciones de estructuras, mejor- privilegiados son definitorios, sí, pero no definitivos:

«El acto definitivo — no actualización de estructura, sino acto propiamente dicho, que, si lo es de verdad, será también "instante", "repetición” y "siempre" - es la «hora de la muerte». Pero en la «hora de la muerte» hay que distinguir, a mi parecer, dos aspectos: lo que tiene de suceso -el morir- y lo que tiene de acto humano, de última instancia concedida al hombre para la obra moral de sí mismo. Es importante distinguir estos dos aspectos, porque pueden -y probablemente suelen- presentarse disociados. El instante de la muerte biológica, según muestra la experiencia de la muerte ajena — experiencia, como tal, muy precaria y "exterior"- sobreviene con frecuencia "retrasado", cuando ya el hombre no se posee y lo que queda de él no es sino un residuo inconsciente y comatoso. El padre Karl Rahner ha llamado al último acto en que todavía disponemos de nosotros mismos la "muerte libre", a diferencia de la "muerte biológica". Ahora bien, desde el punto de vista que ahora estamos tratando -el de los actos privilegiados- este es el acto definitivo. Hasta él "había tiempo". El hombre conservaba ante sí algunas -muchas o pocas- posibilidades de modificar su êthos. Desde este instante, el êthos va a quedar definido y terminado, las posibilidades van a quedar fijadas para siempre, agotadas en el ser, coincidentes con él; empezamos a ser, definitivamente, lo que hemos hecho de nosotros mismos, lo que hemos querido ser» ${ }^{17}$.

Y de ahí que destaque las nociones de kairós y de pléroma para la tarea ética, que quedará fijada en el acto definitorio y definitivo de la muerte.

«La perfección ética ha de hacerse en el tiempo y con el tiempo. Nuestros proyectos se forjan en el tiempo, la perfección es cualitativamente diferente a lo largo de los años, la "experiencia de la vida" es experiencia del tiempo vivido. El concepto de kairós, u oportunidad, la enkairía o momento propio, es esencial para la tarea moral. Hay que dar tiempo al tiempo, saber esperar, aprovechar el cumplimiento de todas las condiciones, la realización de todas las posibilidades previamente necesarias, aprovechar el "¡ahora!". Y junto al concepto helénico del kairós, el concepto bíblico del pléroma. Cristo llegó a "su hora", en la "plenitud de los tiempos". Pero también, más modestamente, cada uno de nosotros tiene «su hora»y su «plenitud» para cada una de las partes de su tarea moral. El êthos se va forjando a través de los sucesivos kairoi,

17 Ibidem, pp. 313-314. 
realizando "cada cosa a su tiempo»", sin que se pueda saltar por encima de él. De tal modo que la perfección es cualitativamente distinta no sólo para cada persona, sino también en cada kairós. Por eso la perfección del niño — abertura a la realidad, ojos abiertos ante el mundo, docilidad para lo superior - es cualitativamente diferente de la perfección del joven —entusiasmo, aspiraciones infinitas—, de la perfección del hombre maduro — sentido de lo posible y de que la "paciencia es todo" — y de la perfección del viejo - bendición universal, decir una gran sí de arrepentimiento, aceptación y fidelidad a cuanto se ha sido. La perfección ha de lograrse al hilo del tiempo, sin "adelantarse", y por eso son insatisfactorios el "niño prodigio" y también el "niño empollón", que sofoca al niño auténtico que tendría que haber sido para, a su tiempo, ser verdaderamente hombre. Hay una tarea moral para cada una de nuestras horas y la tarea moral, el êthos, tiene también su tiempo bien determinado, sus «días contados». En esto decía Séneca que nos diferenciamos de los dioses: en que se nos ha dado un tiempo finito. Por lo mismo es más precioso, tenemos que aprovecharlo» ${ }^{18}$.

\section{II.2. OTROS DESARROLLOS}

Las ideas que acabamos de ver vuelven, matizadas o desarrolladas de algún modo en relación al tema abordado, pero sin cambios sustanciales, en otros momentos de la obra de Aranguren. Muy bello, en su brevedad, es su artículo «Fin de año en una muerte 'a la antigua'», publicado originalmente en el diario El País ${ }^{19}$ y recogido más tarde en Sobre imagen, identidady beterodoxia $(1982)^{20}$. Escrito tras asistir durante unos días de la Navidad anterior a un familiar suyo en Barcelona, Aranguren aboga, frente a la fiebre consumista que tanto se estaba desplegando en España (incluso entre los jóvenes, con el paso del hippie al yuppie), por recuperar una cierta sobriedad y sencillez en la manera de vivir. Y ese estilo que preconiza entroncaría con la recuperación de una muerte a la antigua. Una muerte sin estar rodeado de tubos por todas partes, de ajetreo supertecnólogico y la consiguiente separación del paciente de sus familiares y amigos, en el intento de estirar los tropismos de la vida. No se trata, claro, de negar los necesarios cuidados a veces requeridos por un enfermo. Pero esos cuidados no deberían impedir la posibilidad de que cada cual muera con los suyos, de los que quizá quiera despedirse cuando aún hay tiempo, así como afrontar la propia muerte, tarea paulatina a lo largo de la vida, pero decisiva en esos momentos definitivos del morir.

18 Ibidem, p. 316.

19 El País, 9 de enero de 1980.

20 En OC. op.cit., III, pp. 451-452. 
"Yo quisiera que el "morir en casa", rodeado el enfermo de los suyos, volviera a ser la muerte de cada cual: que la muerte recobrase su faz antigua, de tiempo largo y lento de angustia tranquila, de agonía sosegada, si se permite el oximoron, $y$, al final de este "rito de pasaje" y tras cesar del rítmico jadeo que desencaja el rostro, la paz y el retorno de la fisonomía propia, prenda no sé si engañosa o no, pero consoladora, de resurrección. ¿Reconquista de la "muerte propia", como diría un discípulo de Rilke? No creo yo mucho en, ella [...]. Pero sí que hay, puede haber, debe haber una muerte propia, de quienes aman al moribundo, ya que no de él [...]. Los familiares, los amigos, tienen derecho a que esa última imagen $y$, con ella, el final de la representación, no les sea arrebatada. Es sumamente dudoso que a los más de los hombres se les dé ocasión de asistir, bien despiertos, al venir y acercarse de su muerte. Pero, en cambio, vicariamente, todos podemos asistir a la muerte de nuestros moribundos. Ver morir es tan importante como ver vivir».

De ahí que concluya:

«Hace cuarenta años todo hombre de izquierda ponía su esperanza entera en la tecnología. La democracia, si de verdad ha de serlo, tiene ante sí un objetivo digno de ella: conseguir su buen empleo y el desarrollo de la tecnología que preserve, prolongue la vida y aleje la muerte cuanto se pueda, sí, pero sin escamotear ésta con embelecos. La muerte "a la antigua" sigue siendo una buena muerte» ${ }^{21}$.

Cinco años después de Sobre imagen, identidad y heterodoxia, vuelve sobre la cuestión en su obra Moral de la vida cotidiana, personal y religiosa $(1987)^{22}$, en los capítulos IV («La vida y la muerte») y V («Sobre cultura y moral de la muerte y del suicidio») de la Segunda Parte de la misma. En ellos retoma las consideraciones que ya hemos visto, con algún matiz de importancia. Frente a un posible enfoque metafísico o cosmológico de la cuestión, Aranguren elige un enfoque existencial, de acuerdo con el cual propone una tipología de cuatro modelos de relación entre la vida y la muerte. La contradicción entre la vida y la muerte, a la manera de Epicuro, de manera que, al no coincidir una y otra, mi muerte sería siempre, como Sartre pensaba, muerte para los otros. Y si, frente a Rilke, no puede haber una «muerte propia» para uno mismo, sí puede y debe haber una muerte propia de quienes amaron al difunto:

«Pues verdaderamente la vida es representación y la muerte es, en el más grave sentido de la palabra, un gran espectáculo, el último "rito de pasaje" al que nos es dado asistir. Ver morir es algo supremamente serio. Serio para cada una de las personas próximas, por uno u otro concepto, al que está muriendo; serio para la comunidad a la que el muerto perteneció. Son los amantes y amigos suyos quienes le convierten en inolvidable [...].

21 Ibidem.

22 En OC op.cit, II, 673-752. 
Mas es menester agregar que hoy el auténtico “ver morir”, como espectáculo seriamente dramático, está empezando a ser suplantado por el degradante espectáculo, apto para morbosos degustadores de la violencia, de poder presenciar la "muerte en directo"»."

A ese primer modelo Aranguren agrega el de la vida en función de la muerte (como en la concepción estoica o la del primer Heidegger), el de la muerte como limitación de la vida, como el «contexto moral» en el que esta ha de fraguarse, y, por último, muerte en función de la Vida (con mayúscula), bien al modo cristiano occidental, bien al modo de reintegración en el Todo, a la manera de Oriente. Pero sin detenernos más en ellos, ni en las observaciones sobre el suicidio que, comentando el libro de Joan Estruch y Salvador Cardus, Plegar de viure, lleva a cabo en el capítulo siguiente, sí me gustaría llamar la atención sobre el matiz que introduce a propósito de sus anteriores afirmaciones acerca de erigir el momento terminal de la muerte en decisivo en cuanto al valor de toda una vida y, como tal, en destinación eterna. Mas, ¿'es justo, se pregunta, que sea precisamente ese instante, por lo general muy poco kierkegaardiano, el que defina el perfil axiológico de nuestra vida? Y, aunque sea a modo de pregunta, se responde:

« No ha de ser mas bien la estructura unitaria de esta y los instantes, ahora sí kierkegaardianos, acontecidos a lo largo de ella, no se sabe bien dónde, los que definan - y no a nuestros ojos - lo que en último término, que puede coincidir o no con el terminal, somos y seremos?»». ${ }^{24}$

En 1992, volvió sobre la muerte en su libro La vejez como autorrealización personal y socia ${ }^{25}$. De acuerdo con sus anteriores enfoques, Aranguren defiende que el morir no es, según la terminología escolástica a la que ya había acudido en ocasiones en su Ética, propiamente un acto humano (actus bumanus), sino el último de los actus hominis, puesto que la muerte no es tanto un acto propiamente humano, sino algo que acontece al hombre. Es por ello por lo que, ante todo, morimos para los demás y la muerte es, se quiera o no, un espectáculo, que puede vivirse, según acabamos de recordar, de muy diversas formas, aunque Aranguren vuelve a insistir en su deseo de que «fuera una escena nada espectacular, pero sí decorosa»»

En fin, sin volver a desarrollar tesis que en lo esencial ya hemos consi-

23 Ibidem, p. 732.

24 Ibidem, p. 734.

25 En OC. op.cit., $\mathrm{V}$,, especialmente en el capítulo $\mathrm{X}$ ( $\mathrm{El}$ anciano ante la muerte») y en el Apéndice

26 Ibidem, p. 646. 
derado, no querría concluir sin recordar un texto muy hermoso, perteneciente a la conversación que con él mantuvo Javier Muguerza en 199327. En él, Aranguren retoma un tema amplia y variadamente tratado en su obra, como es el de la relación entre la vida y la literatura ${ }^{28}$, y se refiere a los «textos vivos». La expresión procede de un episodio de nuestra historia universitaria, la separación de los profesores krausistas del siglo diecinueve de sus cátedras. El krausismo, inspirado en Friedrich Krause, fue difundido especialmente en España a través de la labor de Julián Sanz del Río y más tarde de Francisco Giner de los Ríos, fundador de la Institución Libre de Enseñanza. Expurgados por la autoridad académica los «libros de texto» se pensó que ello no era suficiente y que debía acompañarse de la expulsión de los «textos vivos», como se dio en llamar a los citados profesores, sentando un precedente que acabaría asimismo por afectar, años más tarde, al propio Aranguren. Comentando ese episodio, pero remontándose a una reflexión más general, observa:

«Pero lo cierto es que todos y cada uno de nosotros somos eso, textos vivos. Textos que nuestro "yo reflexivo" va, por así decirlo, escribiendo, contándose a sí mismo, con más o menos tino, al hilo de la vida protagonizada por nuestro «yo ejecutivo». Contar es como vivir y vivir es como contar o, mejor dicho, contarse, de manera que el mundo vivido y el narrado se solapan inevitablemente. Somos o, al menos, nos figuramos ser nuestra propia novela, la "narración narrante" de nuestra vida. Y, como los textos literarios, también los textos que somos requieren de interpretación, razón por la que todos aventuramos, clara o confusamente, nuestra propia hermenéutica».

Y enlazando esas reflexiones sobre vida, literatura y hermenéutica de sí con el sentido que a la vida de cada cual se pueda otorgar tras su muerte, concluye:

«Como también cabe de ellos la exégesis que hagan los demás, si la llegan a hacer, cuando el relato se dé por concluido y nos toque, después de nosotros mismos, la hora de su "comprensión". ¿A quién pedir esa última comprensión que consista no tanto en juzgarnos cuanto en decirnos quiénes somos, quién soy? No sé, tal vez a la Deidad

27 Muguerza, J., «Del aprendizaje al magisterio de la insumisión. (Conversación con José Luis L. Aranguren)». Publicado por primera vez en E. López-Aranguren, J. Muguerza y J. Ma Valverde, Retrato de José Luis L. Aranguren, Madrid: Galaxia Gutenberg - Círculo de Lectores, 1993, se encuentra asimismo recogido como «Epílogo» a la amplia antología de textos que sobre la obra de Aranguren preparé y que ya ha sido recordada (Cf. Gómez, C., José Luis L. Aranguren. Filosofia y vida intelectual op. cit., pp. 371-410, que es por donde citaré).

28 Cfr., Gómez, C., «La vida como narración (Aranguren y Ricoeur)», Daimon, 68 (2016), 67-83. 
ante la cual hayamos existido, siquiera como sueño, de suerte que, si «la vida es sueño», sea, haya sido, esté siendo, vaya a ser sueño «de» Dios. Pero ya digo que no sé». ${ }^{29}$

Dejemos entonces aquí, con esta estremecida esperanza, las reflexiones que desde el punto de vista de la Ética y de la Filosofía de la Religión realizó sobre la muerte José Luis Aranguren.

REFERENCIAS BIBLIOGRÁFICAS:

Aranguren, J. L. L., Obras completas, ed. de F. Blázquez, Madrid: Trotta, 6 vols., 1994-1996.

Ariès, Ph., El hombre ante la muerte, trad. de M. Armiño, Madrid: Taurus, $4^{\mathrm{a}}$ ed., 1992.

Ariès, Ph., Historia de la muerte en Occidente, de la Edad Media hasta nuestros días, trad. de E. Carbajo y R. Perrin, Barcelona: Acantilado, 2000.

Bonete, E., Aranguren: la ética entre la religión y la política, Madrid: Tecnos, 1989.

Bonete, E., «Aranguren: sentido ético de la muerte», Revista de Hispanismo Filosófico, 13 (2008), 75.89.

Castilla del Pino, C., «Recuerdo de José Luis L. Aranguren», Isegoría, 15 (1997), 39-41.

Freud, S., Consideraciones de actualidad sobre la guerra y la muerte, en Obras Completas, trad. de L. López- Ballesteros y de Torres, Madrid: Biblioteca Nueva, $3^{a}$ ed., 1973, T.II.

García-Santesmases, A., Gómez, C. y Muguerza, J., «Homenaje a José Luis L. Aranguren», A Distancia, 1997, pp. XXIX-XXXI de los Cuadernos de Cultura.

García- Santesmases, A. (ed.), José Luis López Aranguren. La izquierda, el poder y otros ensayos, Madrid: Trotta, 2005.

Gómez, C., José Luis L. Aranguren. Filosofía y vida intelectual. Textos fundamentales, Madrid: Trotta-UNED, 2010.

Gómez, C., Freud y su obra. Génesis y constitución de la Teoría Psicoanalitica, Madrid: Biblioteca Nueva-Asociación Psicoanalítica de Madrid, 2002, (3 ed. 2014).

Gómez, C., y Muguerza, J. (eds.), La aventura de la moralidad. Paradigmas, frontera y problemas de la Ética, Madrid: Alianza, 2007 (8 ${ }^{\mathrm{a}}$ ed. 2018).

29 En J. Muguerza, «Del aprendizaje al magisterio de la insumisión. Conversación con José Luis L. Aranguren» op. cit., pp. 409-410. 
Gómez, C., «El oficio del intelectual en J. L. L. Aranguren», Cuadernos bispanoamericanos, 786 (2015), 34-51.

Gómez, C., «La vida como narración (Aranguren y Ricoeur), Daimon, 68 (2016), 67-83.

López-Aranguren, E., Muguerza, J., Valverde, J. Ma: Retrato de José Luis L. Aranguren, Madrid: Galaxia Gutenberg-Círculo de Lectores, 1993.

Muguerza, J. «Del aprendizaje al magisterio de la insumisión. (Conversación con José Luis L. Aranguren)», en E. López-Aranguren, J. Muguerza y J. Ma Valverde, Retrato de José Luis L. Aranguren, cit. Se encuentra asimismo en Gómez, C., José Luis L. Aranguren. Filosofía y vida intelectual

Platón, Fedón, ed. de C. García Gual, en Diálogos. III, Madrid: Gredos, 1986.

Rousseau, J.-J., Las ensoñaciones del paseante solitario, ed. de F. J. Hernández, trad. de C. Ortega Bayón, Madrid: Cátedra, 1986.

Unamuno, M. de, «Mi religión» (1907), en Mi religión y otros ensayos, Madrid: Espasa-Calpe, $\sigma^{a}$ ed., 1973.

Carlos Gómez SÁnchez es catedrático de filosofía moral y política de la UNED. Sus intereses principales han girado en torno a la relación de la Ética con la teoría psicoanalítica (Freud, crítico de la Ilustración, Barcelona: Crítica, 1998; Freud y su obra. Génesis y constitución de la Teoría Psicoanalítica, Madrid: Biblioteca Nueva, 2002) y la Filosofía de la Religión (Ética y religión: una relación problemática, Madrid: Fe y secularidad, 1995), desde una perspectiva prevalentemente contemporánea (Doce textos fundamentales de la Ética del siglo XX, Madrid: Alianza, 2002; La aventura de la moralidad. Paradigmas, fronteras y problemas de la Ética, coeditado con Javuer Muguerza, Madrid: Alianza, 2007; José Luis Aranguren: Filosofía y vida intelectual, Madrid: Trotta, 2010).

Lineas de investigación:

Teoría psicoanalítica, Filosofía de la Religión, Ética, y Freud.

Publicaciones recientes:

- «Amor, ética, justicia», Pensamiento, vol. 74/280 (2018), pp. 349-367.

- «Labilidad de la culpa», en: D. García Marzá, J. F. Lozano, E. Martínez Navarro y J. C. Siurana (eds.), Homenaje a Adela Cortina. Ética y Filosofía Politica, Madrid: Tecnos, 2018, pp. 121-138.

- «¿Por qué y cómo se ocupa el psicoanálisis de la Ética?», en M. Alcaide y T. Oñate (coords.), La cuestión del sujeto ante los retos de la globalización, Madrid: Dykinson, 2019, pp. 83-119.

Dirección electrónica: cgomez@fsof.uned.es 